\title{
El cuerpo en la clínica psicoanalítica
}

\section{The body in the psychoanalytic clinic}

\section{Diana Wolkowicz}

\section{RESUMEN:}

En este artículo se describen e interrogan los efectos en la subjetividad de las nuevas formas de crianza que, de la mano de las nuevas tecnologías dejan al infantil sujeto en dificultades para la construcción de las ficciones necesarias para la vida.

Se describen las dificultades que surgen en los niños cuando el Otro de su cotidianeidad es la lengua de las pantallas que tal como describe Berkoff (Berkoff), es una lengua sin volumen, de Otro que es voz y mirada sin cuerpo. Qué ocurre en estos casos con la dimensión imaginaria, fundamental en los inicios de la vida pero en la que el niño muchas veces queda atrapado, sin que el orden simbólico de la época le facilite la salida.

Se trabaja sobre el final del artículo, el neologismo de Lacan troumatisme, noción que permite desarrollar brevemente la problemática del autismo, tan acuciante en nuestra época

\section{Palabras Clave:}

Cuerpo - imaginario - infancia troumatisme - autismo

\section{Summary:}

This article contains descriptions and questions regarding the effects on subjectivity, brought by the new ways of child rearing, which together with new technologies, deprive the child of the fictions necessary for life.

There is also a description of the difficulties which arise in children when the Otherness in everyday life is represented by the screen languages. Bercoff regards it as a language with no volume, coming from the Other, who is voice and sight, but not body. What happens in these cases with the imaginary dimension, an essential component in the early stages of life and in which the child is often entrapped, without the symbolic order of the time period to help him out.

The end of the article deals with Lacan's neologism "traumatisme". This notion allows for the understanding of the autism issue, a compelling matter of these times.

WORd PAD:

Body - Imaginary - Childhood troumatisme - Autismo 



\section{1-INTRODUCCIÓN}

Un avance de este artículo fue presentado en un panel organizado por ERAPP, (Espacio de Reelaboración, Análisis y Producción de Prácticas) coordinado por la Ps. Wanda Donatto, en el Colegio de Psicólogos de Rosario.

En aquella oportunidad nos interrogábamos a partir del título del panel "El cuerpo en la clínica psicoanalítica”, si acaso organizar un panel sobre esta temática era un intento de darle relevancia al cuerpo como si éste hubiera estado olvidado, relegado de la clínica psicoanalítica.

Frecuentemente se escucha decir a practicantes del psicoanálisis que trabajan con niños o en diferentes instituciones, frases como "hay que poner el cuerpo", como si fuera de alguna manera posible un análisis sin el cuerpo. Si esto fuera así, el psicoanálisis se convertiría sólo en una aventura intelectual. Si necesitamos hablar del cuerpo es porque olvidamos los orígenes del psicoanálisis que no es otro que la pregunta por lo que acontece en el cuerpo de las histéricas. Probablemente este "olvido" del cuerpo tenga que ver con cierta transmisión del psicoanálisis basada en los primeros Seminarios de Lacan, donde el sujeto puede tomarse como un ser de lenguaje y donde pareciera privilegiarse la idea lacaniana de que el psicoanálisis opera en lo simbólico, siguiendo los movimientos del significante y que lo imaginario debería quedar un paso atrás.

Esta sería una transmisión sesgada del psicoanálisis. En sus primeros Seminarios Lacan parte de una revisión del inconsciente freudiano y formula su frase: "El inconsciente está estructurado como un lenguaje" (1987:28). Se trata de un lenguaje transformado ya que en él se ma- nifiesta una verdad del Sujeto. El Sujeto dice más allá de lo que quiere decir, dice cosas que no sabe que dice a partir de lo cual una verdad puede ser localizada. Es la dimensión del lapsus, del chiste, del acto fallido, que le revela al sujeto un deseo que se le escapa.

En la segunda parte de su obra Lacan teoriza y orienta su clínica en torno de privilegiar la satisfacción, el goce en el cuerpo en relación a la experiencia analítica. El inconsciente lacaniano ya no se limita a descubrir en la palabra del sujeto una verdad oculta, sino también un modo de gozar. Ya no se trata tanto de ¿qué quiere decir el síntoma? Sino de ¿cómo goza con eso? ¿dónde está su goce? ¿Cuál es su singular, único modo de gozar?

A partir del Seminario XX se ubica un cambio de perspectiva cuyo pivote es el goce. Lacan pone el acento sobre el cuerpo. Se trata de un cuerpo que goza y que está marcado por pasiones, y afectos. Introduce en este Seminario la noción de cuerpo como "sustancia gozante" (Lacan, 1972:32), aludiendo al viviente como la condición primaria de goce, y al cuerpo como su soporte.

Al final de su enseñanza el sujeto del inconsciente, constituido por el significante, deja paso al parlètre, al hablante en su ser particular de goce. A partir de aquí ya no se tomará sólo en cuenta el aspecto mortificante del significante en el que la palabra mata la cosa, sino que también se considera el aspecto corporizador del significante que implica que la palabra produce un acontecimiento de goce en el cuerpo. Cuando se aprende a hablar, el efecto de la lengua recae sobre el cuerpo y deja allí sus marcas. "Se trata del efecto que produce la lengua sobre el cuerpo cau- 
sándolo, produciendo un cuerpo que sufre y que goza" (Berkoff, M, 2016: 25)

Un cuerpo dice Lacan en el Seminario 23 "es la única consistencia del parlêtre y es lo que tiene que traer al análisis" (2006:63). Tal como señala Lijtinstens (2014), si se tratara sólo de lo simbólico, podríamos llevar un análisis por los medios virtuales. Claramente la experiencia analítica se trata no sólo de palabras sino de la resonancia de un decir en el cuerpo.

\section{2 - El CUERPO EN LAS NUEVAS FORMAS DE CRIANZA}

En el Atolondradicho Lacan dice: "La función de cada uno de sus órganos le hace problema al ser hablante. Es en lo que especifica el esquizofrénico, por estar tomado sin el auxilio de ningún discurso establecido." (1973:474) Señala J.A.Miller (2007), que lo propio del esquizofrénico, es no poder resolver sus problemas de ser hablante, haciendo un llamado a los discursos establecidos, a los discursos típicos. La educación es uno de los discursos que nos dice que hay que hacer con el cuerpo, y es en gran medida, el aprendizaje de las soluciones típicas, de las soluciones sociales para resolver el problema que plantea al ser hablante el buen uso del cuerpo y de las parte del cuerpo. Esta distribución no opera en el esquizofrénico. En la esquizofrenia los órganos pasan fuera del cuerpo, en el sentido que toman vida ellos mismo. ¿Cuáles son los discursos típicos de nuestra contemporaneidad, cuál sería la educación hoy, la que recibe, aloja a los recién llegados al mundo, para que encuentren un discurso que les permita el buen uso del cuerpo y de las partes del cuerpo?
Los relatos de crianza muestran que las regulaciones y cortes que provienen del Otro, se dilatan y postergan asemejándose a los lazos simétricos que entre niños y adultos se producían en los siglos XII al XIV, antes de la construcción de la noción de infancia propia de la modernidad.

Philippe Ariès (1987), sostiene que el sentimiento de infancia, tal como lo conocemos hoy, no estuvo desde siempre en la historia de la humanidad y ubica su surgimiento en el siglo XIV, con los cambios en la estructura de la familia. Los niños dejan de representarse como adultos en miniatura y toman el estatuto de seres humanos vulnerables, sosteniéndose esta idea también desde la Iglesia católica que comienza a nombrarlos como "frágiles criaturas de Dios". A partir de aquí nace una noción de infancia como fase en el ciclo de la vida humana, asimétrica en relación al adulto y fundamentalmente educable. Se ubican a partir de aquí fronteras claras entre la niñez y la adultez que no existían en la edad media.

En la actualidad diferentes autores debaten acerca del fin de la infancia. Es claro que las fronteras entre niños y adultos construidas con la modernidad se ven alteradas. Se observa una cierta infantilización del adulto que conlleva la adultización del niño que se manifiesta en la vestimenta, las comidas, los horarios, los espectáculos, etc. Se trata de una suerte de retorno al lapso comprendido entre los siglos XII al XIV, donde la relación niño adulto era simétrica y donde el niño compartía indiferenciadamente la vida cotidiana con el adulto. Violeta Nuñez (2000), afirma que "se trata de un retorno paradójico ya que no hay retorno a lo premoderno, sino que algo de lo premoderno retorna enganchado en las lógicas brutales de segregación 
propias de la posmodernidad" (p.33). Más que hablar de la desaparición de la infancia hemos de hablar de la desaparición la concepción moderna de infancia.

Se observa en la actualidad un retorno al colecho, con el aprovechamiento del mercado que ofrece cunas que se insertan en la cama de los padres. El amamantamiento a "libre demanda", también prolongado al extremo de ver a niños que llegan caminando y metiendo sus manos en el pecho materno toman posesión del mismo, en una escena que se torna incestuosa y muchas veces obscena. El control de esfínteres también se demora "esperando la maduración”, sin que la demanda del Otro pueda articularse.

En el Seminario 11 Lacan respondiendo a Dolto dice: "La descripción de los estadios de la libido, no debe ser referida a una pseudo maduración natural. Los estadios se organizan en torno a la angustia de castración, que como un hilo perfora todas las etapas del desarrollo, destete, disciplina anal etc. Los estadios son consistentes precisamente en términos de malos encuentros." (1987:72)

Las nuevas formas de crianza sostiene la ilusión, de que el buen encuentro es posible. Y cuando este no se produce se recurre a los objetos que ofrece la tecno-ciencia. Un caso paradigmático que ilustra esto es el de un niño nombrado enurético, medicado por incontinencia a la edad de 6 años. Al finalizar la entrevista la analista interroga: "no me ha quedado claro, ¿cuándo le sacaron los pañales? La respuesta fue: "aún no se los sacamos, estamos esperando que salgan secos". En este caso el objeto de la tecno ciencia: fármaco, se anticipa junto al discurso de la medicina que piensa la enuresis como enfermedad, a la interdicción paterna y a la demanda materna.

Laurent, (2018) en una conferencia dictada recientemente en la UBA, "Los niños de hoy y las parentalidades contemporáneas" dice que el niño de hoy nace en un mundo que ya no está estructurado por el amor del padre, con su doble vertiente, aquel que es al mismo tiempo amado y el que priva de goce. Esta particularidad fragiliza su construcción especialmente porque el niño contemporáneo está confrontado hoy a formas de goce adictivo; está confrontado sin mediación a lo que no cesa de repetirse tanto en la vertiente del demasiado lleno o al demasiado vacío, como en las adicciones que conciernen a todos los circuitos pulsionales: el oral: anorexia-bulimia, el Junk food, las sustancias. El anal: retención- expulsión, agresividad. Lo escópico: juegos de videos y pantallas múltiples y lo vocal, el objeto voz: con las intolerancias a los mandamientos en general.

Podríamos concluir que las nuevas formas de crianza son soluciones típicas de la época que muestran que el goce adictivo que viene del Otro le dificulta al infantil sujeto la cesión de los objetos pulsionales y por ende, que se instale una dialectización entre los objetos y él como sujeto que tiene un cuerpo y que ya no es el cuerpo del Otro.

\section{3 - El CUERPo EN LOS INICIOS DE LA VIDA}

Sabemos que desde el principio el sujeto está inmerso en el lenguaje, pero en los inicio de la vida psíquica la dimensión imaginaria es fundamental. Esto se observa en las pequeñas escenas lúdicas que monta un niño y en la amplitud del campo especular. 
En el "Estadio del espejo" (1949), Lacan sostiene la tesis de que no hay cuerpo para un sujeto antes de que la imagen le haya ofrecido una unidad, le haya dado consistencia a la experiencia propioceptiva del organismo, siempre desmembrada.

Es importante hace hincapié en que el sentimiento de unificación del cuerpo, está unido a una experiencia de júbilo en el bebé, "la imagen especular es asumida jubilosamente por el ser sumido todavía en la impotencia motriz" (p.86). En la experiencia de tener un cuerpo como unidad se localiza una satisfacción pulsional, una experiencia de goce. Tal como afirma Bassols (2015), el cuerpo imaginario es un modo de nombrar este momento inaugural de inyección de goce en el cuerpo.

El mundo estructurado por el estadio del espejo es un mundo de transitivismo donde la imagen del cuerpo se confunde con la del otro, donde el otro y el yo se confunden. Es muy frecuente escuchar hablar en tercera persona a niños pequeños, más aún en nuestra época donde el niño está expuesto desde muy temprano a las pantallas: tv para dormir, videítos que reemplazan muchas veces los cuentos y jueguitos del celular. Niños que hablan como el Otro, en neutro, con tonadas diferentes a la de sus padres; confundidos con el otro de la pantalla. Claramente lo dice Berkoff: "Se le ofrece al niño la lengua aplanada de la pantalla, una lengua sin volumen. La pantalla funciona como Otro que es voz y mirada sin cuerpo" (2014:25)

Plantea Miller (2015), que el estadio del espejo es la primera estructura del mundo primario del sujeto, lo que indica que es un mundo muy inestable, de arenas movedizas y es a partir de ahí que se estructura la psicosis. El neurótico sale del espejo con un cuerpo unificado que creer tener, y hace de él algo agalmático o valioso en relación al objeto. En la psicosis se asemeja a un estallido, no hay conciencia del cuerpo.

Un analista trabajando en una institución con niños psicóticos relata como aprendió esto el día que mandó a bañarse a un niño. Cuando el niño se metió en la bañadera no se movió. Entonces le dijo lávate y siguió sin moverse hasta que le dijo empieza por las manos y entonces se lavó las manos y apoyó el jabón y ahí entendió que el decir lávate puede comprenderse desde la idea neurótica de cuerpo entero que no era el caso de ese niño.

El mundo imaginario es también para Lacan el mundo del deseo de la madre, cuya fuerza pulsional es el deseo desordenado de la madre con respecto al niño. El mundo primario, imaginario es un mundo de locura.

Continúa Miller diciendo que, el orden viene al mundo imaginario con lo simbólico. Lo simbólico, donde Lacan ubica el lenguaje y la metáfora paterna, impone el orden, la constancia, la jerarquía que estabiliza el mundo imaginario movedizo.

Lacan condensa esta potencia ordenatriz de lo simbólico con el Nombre del Padre, que es un elemento que produce como consecuencia un goce en menos. Si el goce imaginario que está en demasía continúa existiendo, entonces el Nombre del padre no es operatorio.

En los niños pequeños detenidos en su constitución subjetiva se puede observar y escuchar esta salida del estadio del espejo y como comienza a operar la metáfora paterna. Son casos donde el trayecto que va de la posición de objeto a la de Sujeto se dificulta. Se trata de niños perdidos en la dimensión imaginaria, que viven en un presente continúo, sin que lo simbóli- 
co ordene. Muchos comienzan a hablar tardíamente y cuando lo hacen abundan las literalizaciones y ecolalias, frecuentemente hablan en tercera persona sin poder nombrarse como Yo, confundiéndose con algún personaje de las pantallas, donde se muestra como el transitivismo del estadio del espejo se prolonga más allá de los tiempos cronológicos habituales. Muchas veces no se trata de casos de psicosis, ya que après coup se comprueba que se ha estructurado una neurosis infantil, pero son casos que nos permiten palpar la salida del espejo que la teoría nos enseña.

\section{4- EL troumatisme Y EL PROBLEMA DEL AUTISMO}

En El seminario 21 (1973-74), clase del 19 de febrero, Lacan propone el neologismo troumatisme, jugando con trou- agujero y traumatisme-trauma, para designar justamente esa colisión traumática entre el lenguaje y organismo que produce por un lado lalengua y su goce, y por otro lado un agujero en el cuerpo. A partir de aquí el agujero ocupará un lugar fundamental. La percusión del significante en el cuerpo produce el agujero central alrededor del que las tres dimensiones R.S.I podrán anudarse, al mismo tiempo que deja una marca de goce.

En el documental "A cielo abierto" de Mariana Otero, se le pregunta a un analista ¿qué es un cuerpo? Y él elige responder con una metáfora que explica claramente la idea de troumatisme.

Imaginemos que el cuerpo es la tierra y un meteorito que arriba es el lenguaje. Algunos sujetos aceptan el lenguaje, ese meteorito que llega, otros no. En la neurosis de ese choque cuerpo lenguaje hay un trocito que se va y que llamamos objeto a. Ese trocito perdido Lacan lo llamará "objeto causa del deseo”. El neurótico está siempre a la búsqueda de ese objeto y ese objeto está en el Otro. Se inscribe una falta. En el psicótico ese trocito no se pierde y Lacan dice que el sujeto psicótico lo lleva en el bolsillo y el efecto que esto produce es que el mundo entero empieza a girar en torno de él. El Sujeto no busca el objeto a en el Otro como en la neurosis sino que el Otro lo busca en él. El mundo entero quiere algo de él, quiere cosas de él aterradoras, negativas, incomprensibles. Por eso en la dirección del tratamiento en la psicosis es importante no ocupar el lugar del Gran otro aterrador, completo, que goza del sujeto, sino conviene ubicarse como un pequeño otro, un semejante y que las reglas sean recibidas desde afuera.

En el autismo la colisión traumática del cuerpo con lalangue no agujerea lo real del cuerpo y este no puede bordearse con ficciones. En estos casos el sujeto se defiende, inscribiendo el significante S1 sólo, como pura inscripción primaria del goce, sin que se produzca la articulación discursiva entre el S1 y el S2.

Laurent (2013), sostiene que si no hay agujero no hay borde que lo delimite. Si el borde es una zona fronteriza donde se producen los intercambios, el cuerpo caparazón en el autismo, funcionaría como un neo borde, como pura superficie, que adviene de un cuerpo cuyos orificios están tapados.

En el autismo el sujeto queda detenido en relación al lenguaje, donde se encadenan los significantes. El lenguaje en tanto sistema de significantes tiene reglas de oposición y de ordenamiento metafórico y metonímico precisas, precedido por un 
tiempo lógico anterior, el de lalangue. Esta es definida por Lacan como una integral de equívocos compuesta por palabras sin sentido, los S1, que marcan el cuerpo en un tiempo lógico anterior al de la construcción del lenguaje. Lalangue es demasiado privada para servir a la comunicación, "su invariabilidad y su inercia hacen de ella una lengua muerta, incluso si aún está en uso" (Lacan, 2001:73).

Juan Ritvo (2003), sostiene que aquello que Lacan denomina lalangue tiene que transformarse en (la)-langue. Tiene que pasar del murmullo y la confusión, de la dispersión carente de orientación, de la acumulación de sentidos históricamente constituidos, de las trampas y facilitaciones de la homofonía, a la diferenciación, a la heterogeneidad, a la multiplicación de planos y a la integración de los niveles de la experiencia.

Este pasaje no se produce en el autismo. Si la inclusión del sujeto en el lenguaje le da un orden a la estructura, en el autismo el Uno del goce no se borra, hay una detención, un congelamiento y el sujeto permanece y al mismo tiempo se defiende del murmullo de lalengua.

\section{5- PARA CONCluir}

A partir de la noción de trauma entendida por Lacan como el agujero que se produce en lo real del cuerpo por el encuentro con lalengua, los seres parlantes construimos ficciones. Berkoff explica que "Cuando se produce la articulación discursiva entre el S1 y el S2, se arman ficciones que recubren el agujero. El niño, al cernir el objeto en el circuito pulsional, va armando bordes donde se articulan sentido y goce (S2 y a). Podemos decir entonces, que la pulsión queda articulada en un circuito que pasa por el Otro".

Las ficciones actuales de crianza dificultan muchas veces que este circuito se articule. Así es como llegan niños a la consulta sin poder construir las ficciones necesarias para la vida, niños fijados a sus objetos, inscribiendo el significante S1 sólo, como pura inscripción primaria del goce que itera, sin encontrar un punto de capitón, no pudiendo leer esa marca con un dos. Niños que no son necesariamente autista, ni psicóticos, pero que no cesan de repetir el mismo juego, con los mismos objetos y que rápidamente se vivifican en el encuentro con un analista que produce cortes y alternancias en esa fijeza adictiva, aburrida y mortificante.

\section{REFERENCIAS BIBLIOGRÁFICAS}

Lacan, Jacques, (1987) El Seminario 11. Los cuatro conceptos fundamentales del psicoanálisis, Buenos Aires, Paidos.

LaCAN, Jacques, (2001) El Seminario 20, Aún, 1972, Buenos Aires, Paidós.

Berkoff, Mirta (2016) "Hijos de una lengua sin volumen", en Notas de niños. Revista d psicoanálisis del Departamento de Investigación de Psicoanálisis con niños CIEC-NRC. Año $1 \mathrm{~N}^{\circ} 1$ Junio. 
Lijtenstens, Claudia, (2016) “¿Cómo escuchamos el decir del cuerpo de un niño?” en Notas de niños. Revista d psicoanálisis del Departamento de Investigación de Psicoanálisis con niños CIEC-NRC. Año $1 \mathrm{~N}^{\circ} 1$ Junio.

Lacan, Jacques, (2006) El Seminario, libro 23: El sinthome, 1975-76, Buenos Aires, Paidós.

LaCAN, Jacques, (1988) "El estadio del espejo como formador de la función del yo", Escritos 1, Buenos Aires, Siglo XXI.

LACAN, Jacques, (2001) "El Atolondradicho" en Otros escritos, Buenos Aires, Paidós.

Miller, Jacques Alain, (2007) "La invención psicótica” en Virtualia No. 16. Revista Digital de la Escuela de la Orientación Lacaniana EOL. En: Formas contemporáneas de la psicosis. Buenos Aires: EOL, Febrero/marzo.

Ariès, Philipe, (1987) El niño y la vida familiar en el Antiguo Régimen. Taurus, Madrid.

NuÑEZ, Violeta, (2000) "La infancia posmoderna” en Revista El Niño N6, del Centro Interdisciplinario de Estudios sobre el Niño (CIEN), Paidós, Barcelona.

LaCAN, Jacques, (1987) El Seminario 11 Los cuatro conceptos fundamentales del psicoanálisis, 1964, Buenos Aires, Paidós.

LAURENT, Eric, https://www.youtube.com/ watch? $\mathrm{v}=\mathrm{j}-\mathrm{Y} 89 \mathrm{~V} 6 \mathrm{ofHo}$

BAssols, M.,http://www.congressoa mp2016.com/pagina.php?are$\mathrm{a}=8$ \& pagina $=38$ \&lang $=$ en\&lang=es
LACAN, Jacques, (2004) El seminario, libro10: La Angustia, Buenos Aires, Paidós

Miller, Jacques Alain, (2015) “Efecto retorno de la psicosis ordinaria" en Consecuencias, Revista digital de psicoanálisis, arte y pensamiento. $\mathrm{N}^{\mathrm{o}} 15$ Mayo

Lacan, Jacques, El Seminario, libro 21, inédito

LAURENT, Eric, (2013) La batalla del autismo. De la clínica a la apolítica. Buenos Aires, Grama.

Lacan, Jacques, El Seminario, libro 20: Aún, Buenos Aires, Paidós, 2001

Ritvo, Juan Bautista, http://www.imagoagenda.com/articulo.asp?idarticu$\underline{\mathrm{lo}=644}$

Berkoff, Mirta (2014) "Límites y Dificultades en la práctica. Perturbar la defensa en niños", en Revista Virtualia. $N^{\circ} 28$. Julio. Escuela de Orientación Lacaneana. Buenos Aires. http://virtualia.eol.org.ar/028/vitualia Consulta: $18 / 07 / 14$

RESEÑA CURRICULAR DEL AUTOR

Diana Wolkowicz es psicoanalista. Docente e investigadora Facultad de Psicología UNR.

Participante de la Eol sección Rosario. Miembro del equipo interdisciplinario del Centro del Desarrollo Infantil. 